\title{
Effectiveness of salvage radiotherapy for superficial esophageal Cancer after non- curative endoscopic resection
}

\author{
Ikuno Nishibuchi $1^{*}$ (D), Yuji Murakami ${ }^{1}$, Yoshinori Adachi ${ }^{1}$, Nobuki Imano ${ }^{1}$, Yuki Takeuchi ${ }^{1}$, Ippei Tkahashi ${ }^{1}$, \\ Tomoki Kimura', Yuji Urabe'2, Shiro Oka ${ }^{3,2}$, Shinji Tanaka ${ }^{4,2}$ and Yasushi Nagata'
}

\begin{abstract}
Background: Endoscopic resection is widely used as an effective treatment for superficial esophageal cancer. However, the risk of lymph node metastasis increases in cases of muscularis mucosae or deeper invasion, for which additional treatment such as radiotherapy or surgery is required. Accordingly, the current study investigated the efficacy and toxicity of salvage radiotherapy after non-curative endoscopic resection as an organ preservation strategy.

Methods: We retrospectively reviewed 37 esophageal cancer patients who received salvage radiotherapy after noncurative endoscopic resection. The pathological invasion depths were the muscularis mucosae, submucosal layer, and muscularis propria in 14,22, and one patient, respectively. All patients received external beam radiotherapy. Among them, eight received intraluminal brachytherapy following external beam radiotherapy. Elective nodal irradiation was administered to all patients. Twenty-five patients received concurrent platinum and fluorouracilbased chemotherapy.

Results: The median follow-up time was 74 months (range: 3-212). The 5-year progression-free survival and overall survival rates were 64 and 78\%, respectively. No local or regional lymph node recurrence was observed. The causes of death included esophageal cancer in one patient, metachronous esophageal cancer in one patient, other malignancies in eight patients, and other causes in six patients. Late cardiac toxicities $\geq$ grade 3 were observed in six patients, one of whom died of arrhythmia.

Conclusions: Salvage radiotherapy after non-curative esophageal endoscopic resection is an effective treatment as an organ preservation strategy. Although muscularis mucosae and submucosal cancer have a high risk of lymph node metastasis, our results suggest that elective nodal irradiation contributes to reduced regional node metastases.
\end{abstract}

Keywords: Superficial esophageal cancer, Endoscopic resection, Radiotherapy, Elective nodal irradiation

\footnotetext{
* Correspondence: ikuno@hiroshima-u.ac.jp

${ }^{1}$ Department of Radiation Oncology, Graduate School of Biomedical and

Health Sciences, Hiroshima University, 1-2-3 Kasumi, Minami-ku, Hiroshima 734-8551, Japan

Full list of author information is available at the end of the article
}

(c) The Author(s). 2020 Open Access This article is licensed under a Creative Commons Attribution 4.0 International License, which permits use, sharing, adaptation, distribution and reproduction in any medium or format, as long as you give appropriate credit to the original author(s) and the source, provide a link to the Creative Commons licence, and indicate if changes were made. The images or other third party material in this article are included in the article's Creative Commons licence, unless indicated otherwise in a credit line to the material. If material is not included in the article's Creative Commons licence and your intended use is not permitted by statutory regulation or exceeds the permitted use, you will need to obtain permission directly from the copyright holder. To view a copy of this licence, visit http://creativecommons.org/licenses/by/4.0/. The Creative Commons Public Domain Dedication waiver (http://creativecommons.org/publicdomain/zero/1.0/) applies to the data made available in this article, unless otherwise stated in a credit line to the data. 


\section{Background}

Recently, the number of patients with superficial esophageal cancer has tended to increase due to the development of endoscopic equipment [1]. The risk of lymph node metastasis in tumors confined to the epithelium and lamina propria mucosae is extremely low. Endoscopic resection (ER), including endoscopic mucosal resection (EMR) or endoscopic submucosal dissection (ESD), is recommended as standard therapy for these patients, because of the high local tumor control rate and minimal invasion. However, the risk of lymph node metastasis increases in cases with muscularis mucosae (MM) or deeper invasion. Lymph node metastasis occurs in $10-20 \%$ of MM or upper submucosal layer (SM1) invasion and $40-60 \%$ of the middle submucosal layer (SM2) or lower submucosal layer (SM3) invasion [2-7]. Careful observation is sometimes selected for cases of MM invasion with negative margins and no lymphovascular invasion (LVI). However, additional treatment is required in cases of $\mathrm{MM}$ invasion with positive margins or LVI or SM invasion. Although esophagectomy with lymph node dissection is considered standard therapy in these cases, radical surgery is highly invasive and related to increased morbidity and mortality [8-10].

Until 2002, our institution commonly performed intraluminal brachytherapy (IBT) combined with external beam radiotherapy (EBRT) for the treatment of superficial esophageal cancer. We previously reported the long-term treatment results in patients with superficial esophageal cancer who received this treatment [11]. Favorable treatment outcomes in mucosal cancer were achieved in that study. In addition, recent studies reported a comparable outcome of definitive concurrent chemoradiotherapy (CCRT) for superficial esophageal cancer to that of surgery [12-14]. Radiotherapy is less invasive than surgery and has an advantage as an organ preservation method. However, little is known about the safety and efficacy of salvage radiotherapy (RT) after EMR or ESD $[15,16]$. Therefore, this study retrospectively evaluated the efficacy and toxicity of salvage RT as an organ preservation strategy for superficial esophageal cancer with MM or deeper invasion after non-curative EMR or ESD.

\section{Methods}

\section{Patient and tumor characteristics}

Thirty-seven patients with esophageal cancer treated with ER followed by RT with curative intent at Hiroshima University between 2000 and 2014 were eligible for this analysis. One patient who was lost to follow-up just after treatment was excluded from the analysis. The patient and tumor characteristics are summarized in Table 1. The median age of the 34 male and three female patients was 67 years (range: $53-85$ ). Double cancers were observed in 16 patients. Among them, five had concurrent double
Table 1 Patient and tumor characteristics

\begin{tabular}{|c|c|}
\hline Characteristics & No. of patients (\%) \\
\hline \multicolumn{2}{|l|}{ Age (years) } \\
\hline Range & $53-85$ \\
\hline Median & 67 \\
\hline \multicolumn{2}{|l|}{ Sex } \\
\hline Male & $34(92)$ \\
\hline Female & $3(8)$ \\
\hline \multicolumn{2}{|l|}{ Performance status score } \\
\hline $0-1$ & $34(92)$ \\
\hline $2-3$ & $3(8)$ \\
\hline \multicolumn{2}{|l|}{ History of double cancer } \\
\hline Yes & $16(43)$ \\
\hline No & $21(57)$ \\
\hline \multicolumn{2}{|l|}{ History of heart disease } \\
\hline Yes & $9(24)$ \\
\hline No & $28(76)$ \\
\hline \multicolumn{2}{|l|}{ Histology } \\
\hline Squamous cell carcinoma & $37(100)$ \\
\hline \multicolumn{2}{|l|}{ Tumor location } \\
\hline Cervical & $1(3)$ \\
\hline Upper thoracic & $5(13)$ \\
\hline Middle thoracic & $23(62)$ \\
\hline Lower thoracic or Esophagogastric junction & $8(22)$ \\
\hline \multicolumn{2}{|l|}{ Tumor length $(\mathrm{cm})$} \\
\hline Range & $0.8-10$ \\
\hline Median & 3 \\
\hline \multicolumn{2}{|l|}{ Circumference } \\
\hline$<3 / 4$ & $25(67)$ \\
\hline$\geq 3 / 4$ & $4(11)$ \\
\hline Entire & $4(11)$ \\
\hline Unknown & $4(11)$ \\
\hline \multicolumn{2}{|l|}{ Methods of endoscopic resection } \\
\hline EMR & $22(59)$ \\
\hline ESD & $15(41)$ \\
\hline \multicolumn{2}{|l|}{ Depth of pathological invasion } \\
\hline Muscularis mucosae & $14(38)$ \\
\hline Submucosal layer & $22(59)$ \\
\hline Muscularis propria & $1(3)$ \\
\hline \multicolumn{2}{|l|}{ Resection margin } \\
\hline Negative & $10(27)$ \\
\hline Positive & $17(46)$ \\
\hline Non-assessable & $6(16)$ \\
\hline Unknown & $4(11)$ \\
\hline
\end{tabular}

$E M R$ endoscopic mucosal resection, ESD endoscopic submucosal dissection 
cancer. Nine patients had a history of heart diseases, including hypertension in four patients, ischemic heart disease (IHD) in three patients, hypertension and IHD in one patient, and dilated cardiomyopathy in one patient. All patients had squamous cell carcinoma. The Nodal stage was determined by using computed tomography (CT) until 2010 and by using CT and positron emission tomography (PET)-CT from 2011. PET-CT was performed in 11 patients. The circumference of tumor was less than threequarters in 25 patients, equal to or more than threequarters in four patients, entire in four patients, and unknown in four patients. Twenty-two patients received EMR and 15 patients received ESD. The pathological invasion depths were the MM in 14 patients, SM in 22 patients, and MP in one patient. For patients with MM invasion, additional RT was administered in cases with a positive margin, LVI, or high risk of lymph node metastasis as judged by the gastroenterologists. Written and informed consent for RT was obtained from each patient before treatment. This retrospective analysis was approved by the institutional review board.

\section{Treatment}

\section{Radiotherapy}

Before performing a planning CT, metallic clips were placed endoscopically to indicate the excision region. EBRT was performed using a megavoltage photon beam (6-18 MV). Elective nodal irradiation (ENI) was administered to all patients and boost irradiation was performed after ENI. The clinical target volume (CTV) for ENI according to the primary tumor sites were cervical, supraclavicular, and upper mediastinal lymph nodes (LNs) for cervical tumors; supraclavicular, upper mediastinal, and subcranial LNs for upper thoracic tumors; upper to lower mediastinal and perigastric LNs for middle thoracic or lower thoracic tumors; and middle to lower mediastinal, perigastric and celiac artery LNs for esophagogastric junction tumors. Three-dimensional RT planning was performed for all the patients. ENI was performed by using anterior- posterior opposing beams in 20 patients, multi-portal beams in 16 patients and intensitymodulated radiation therapy (IMRT) in one patient. The IBT boost was used in combination with EBRT in eight patients, until 2002.

EBRT and IBT combination IBT was performed using the high-dose-rate iridium-192 remote after loading system. A double-balloon applicator was used for IBT. The outer diameter of the applicator was $20 \mathrm{~mm}$. The prescribed dose was calculated at a depth of $5 \mathrm{~mm}$ from the surface of the esophageal mucosa. Irradiation doses of EBRT were $54 \mathrm{~Gy} / 27$ fractions in cases of MM or SM1 invasion and $60 \mathrm{~Gy} / 30$ fractions in case of SM2 or SM3 invasion. The median ENI dose was $44 \mathrm{~Gy} / 22$ fractions (range: 44-45 Gy). The IBT boost was generally performed immediately after EBRT and the dose was 10 Gy/4 fractions. An excision region with a 2-cm longitudinal margin was irradiated.

EBRT alone Twenty-nine patients were treated by EBRT alone. The median ENI dose was $40 \mathrm{~Gy} / 20$ fractions (range: $40-48 \mathrm{~Gy}$ ) and the median total dose was 60 Gy/30 fractions (range: 50.4-66 Gy). An accelerated hyper-fractionation (AHF) schedule was used in two patients. CTV for boost was defined as an excision region with a $2 \mathrm{~cm}$ margin in the longitudinal direction.

\section{Chemotherapy}

Twenty-five patients received concurrent chemotherapy. The RT procedure was EBRT alone in 24 patients. The selection of chemotherapeutic regimen and reduction of chemotherapeutic dosages were determined according to the protocol at that time and the clinician's judgment. The chemotherapeutic regimens were as follows: cisplatin/fluorouracil (5FU) in 14 patients, nedaplatin/5FU in 10 patients, and carboplatin/5FU in one patient.

\section{Analysis}

The clinical data were updated in April 2020. Overall survival (OS) was defined as the time from the initiation of RT to death from any cause. Progression-free survival (PFS) was defined as the time from the initiation of RT to disease progression, death for any reason, or diagnosis of esophageal metachronous cancer. Esophageal metachronous cancer was defined as the secondary cancer detected in a different site from primary lesion after RT by endoscopy and was not included in local failure in this analysis. The Kaplan-Meier method was used to calculate survival rates. Log-rank tests were used to compare survival curves in univariate analysis. Comparison of data was analyzed by Fisher's exact test. $P$-values $<0.05$ were considered to indicate statistical significance. The Common Terminology Criteria for Adverse Events, version 4.0 (CTCAE v. 4.0) were used to assess toxicities. Acute and late toxicities were defined as events that occurred within or after three months from RT initiation, respectively.

\section{Results \\ Survival and failure patterns}

The median follow-up time was 74 months (range, 3-212 months) for all patients and 75 months (range, 49-209 months) for survivors. The 5-year OS and PFS rates were $78 \%$ (95\% confidence interval [CI], 64-91\%) and 64\% (95\%, CI $49-80 \%$ ), respectively (Fig. 1). There was no significant difference in OS between chemoradiotherapy (CRT) and RT alone (Fig. 2). Regarding failures, no local or regional recurrences were observed. Distant failures were observed in two patients (5\%): distant lymph node metastases in one patient treated by CCRT and carcinomatous pleurisy in one patient 


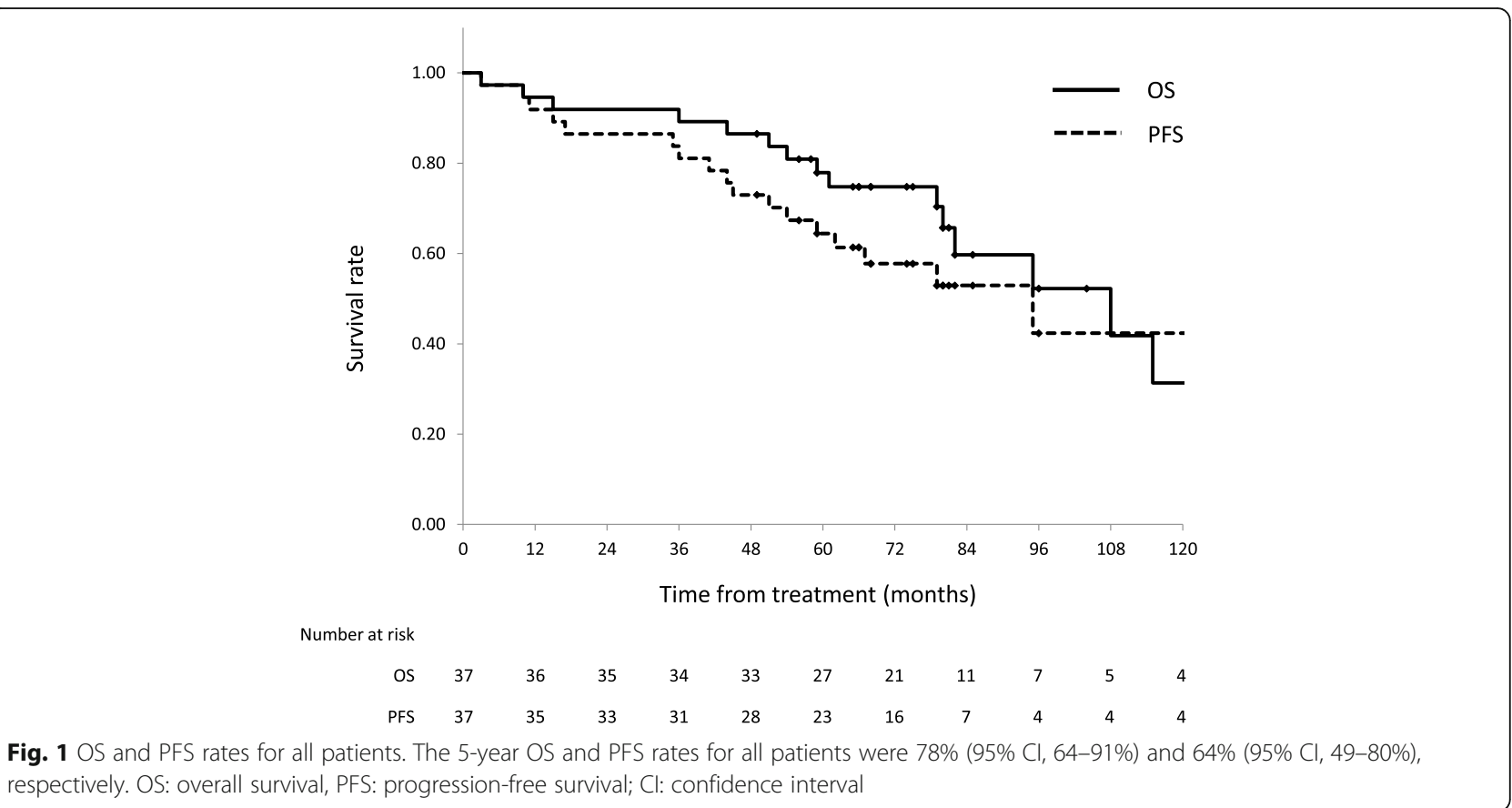

treated by EBRT and IBT. The patient who suffered distant lymph node metastasis in the supraclavicular fossa and abdominal para-aortic region (both sites were outside the RT field) at 45 months after CCRT underwent salvage surgery and postoperative CCRT. He died of arrhythmia and heart failure at 61 months after CCRT, with no evidence of recurrence of esophageal cancer after salvage treatment.

\section{Metachronous esophageal cancer and other malignancies} Metachronous esophageal cancer was observed in seven patients (19\%). The median duration from the end of treatment to diagnosis of the metachronous tumor was 60 months (range, 16-203 months). The 5-year incidence rate of metachronous tumors was $13 \%$ (95\% CI, 0.9-24.8) (Fig. 3). The relation between metachronous

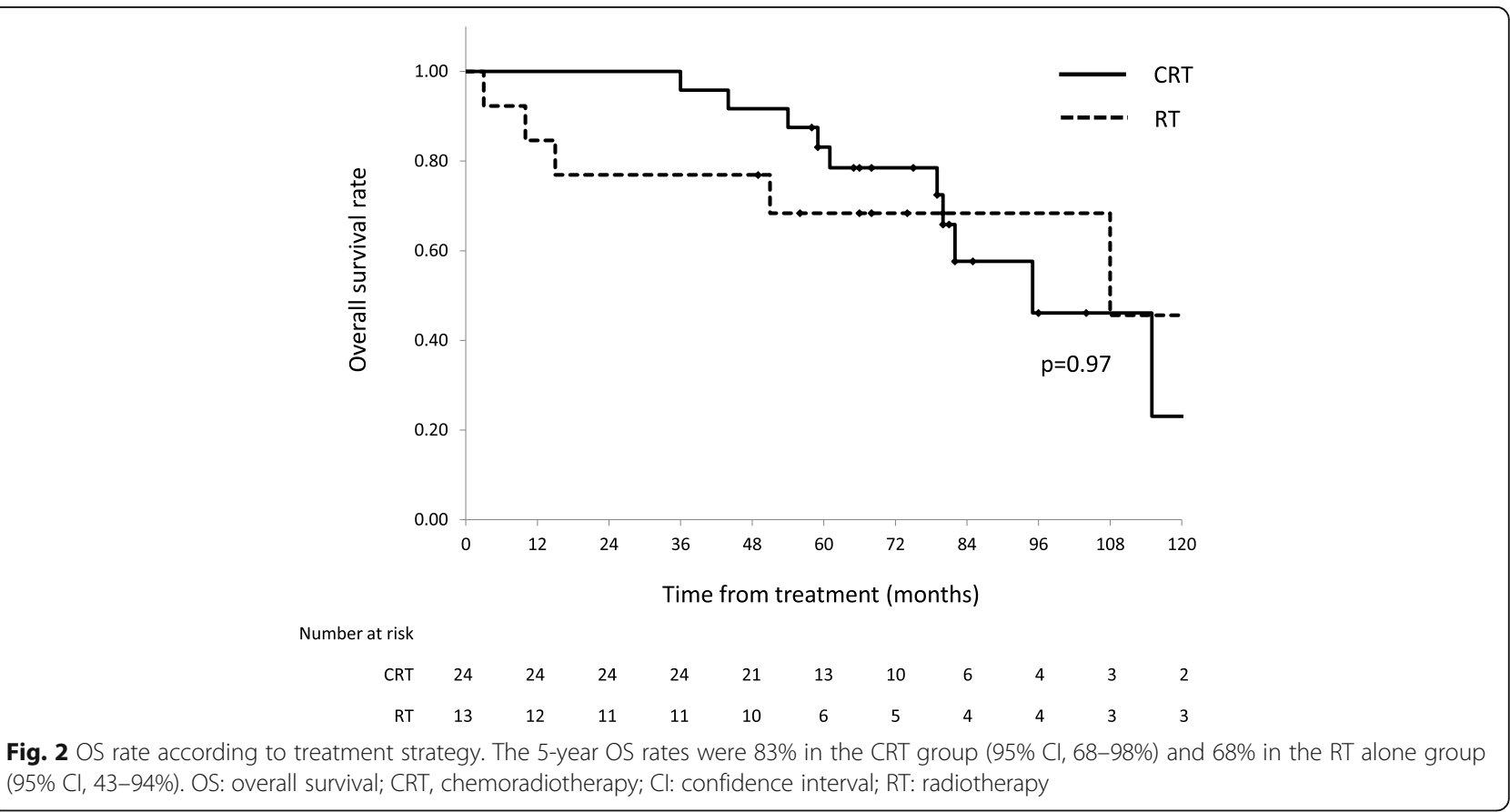




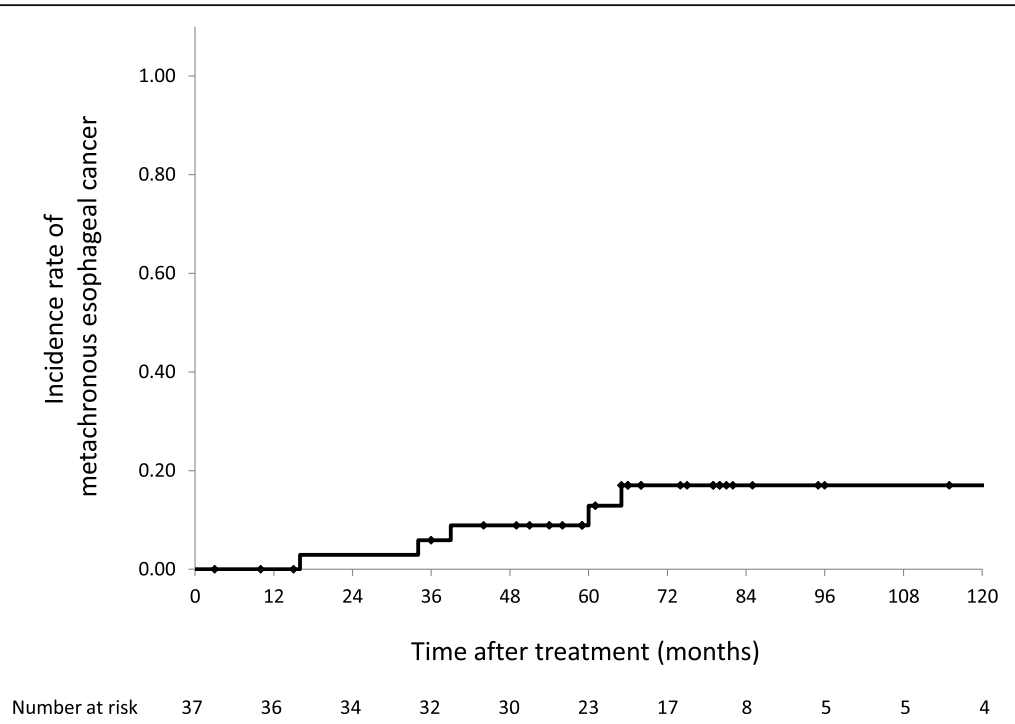

Fig. 3 Incidence rate of metachronous tumor. The 5 -year incidence rate of metachronous tumors was 13\% (95\% confidence interval, 0.9-24.8\%)

esophageal cancer and irradiation field was following: within boost field in two patients, within ENI field in three patients and outside the field in two patients. As both cases of metachronous esophageal cancer within the boost field were away from the excision scar, we diagnosed them as newly occurred esophageal cancer and not recurrence. Five patients were salvaged by ER. One patient with a submucosal lesion concurrently suffered leukemia and received best supportive care because of the poor performance status and older age. One patient refused treatment and died of esophageal cancer.

Double cancer after initial treatment was observed in 15 patients $(41 \%)$. One patient had three malignancies and four patients had two malignancies: head and neck cancer in six patients, gastric cancer in five patients, colorectal cancer in two patients, hepatocellular carcinoma in two patients, malignant lymphoma in two patients, and single cases each of lung cancer, bile duct carcinoma, pancreatic carcinoma, and leukemia. All patients with gastric cancer were diagnosed as superficial carcinoma and salvaged by ER.

\section{Causes of death}

At the time of the last follow-up, 16 of 37 patients had died. One patient with carcinomatous pleurisy died of esophageal cancer. One patient died of metachronous esophageal cancer that occurred 17 years after the initial treatment. Eight patients died of other malignancies, including head and neck cancer in three patients and single cases each of bile duct carcinoma, pancreatic carcinoma, hepatocellular carcinoma, malignant lymphoma, and leukemia. All cases were double cancer occurring after RT. Six patients died of other causes: single cases each of pneumonia, heart failure, respiratory failure, renal failure, senility, and traffic accident.

\section{Toxicity}

The toxicities are summarized in Table 2. Grade 3 or worse acute toxicities of esophagitis, leucopenia, thrombocytopenia, and renal function occurred in two (5\%), 12 (32\%), two (5\%), and one (3\%) patient, respectively. Grade 5 acute toxicity was not observed. In patients treated by RT alone, grade 3 or worse acute toxicity was not observed. Grade 2 esophageal stenosis occurred in seven (19\%) patients and was significantly higher in patients with tumor circumference equal to or more than $3 /$ $4: \geq 3 / 4$ in six patients and $<3 / 4$ or unknown in one patient $(p<0.001)$. Grade 3 or worse esophageal stenosis was not observed. Grade 2 pericardial effusion was observed in $13(35 \%)$ patients. CTCAE v4.0 defines grade 2

Table 2 Toxicities

\begin{tabular}{lllll}
\hline Toxicities & \multicolumn{2}{l}{ No. of patients (\%) } & \\
\cline { 2 - 4 } & Grade 2 & Grade 3 & Grade 4 & Grade 5 \\
\hline Acute & $2(5)$ & $2(5)$ & 0 & 0 \\
Esophagitis & $1(3)$ & 0 & 0 & 0 \\
Nausea & $12(32)$ & $12(32)$ & 0 & 0 \\
Leucopenia & $3(8)$ & $1(3)$ & $1(3)$ & 0 \\
Thrombocytopenia & $3(8)$ & $1(3)$ & 0 & 0 \\
Renal function & $7(19)$ & 0 & 0 & 0 \\
Late & $4(11)$ & 0 & 0 & 0 \\
Esophageal stenosis & $1(3)$ & 0 & 0 & 0 \\
Pleural effusion & $13(35)$ & $1(3)$ & $1(3)$ & 0 \\
Radiation pneumonitis & 0 & $1(3)$ & 0 & 0 \\
Pericardial effusion & 0 & $2(5)$ & $1(3)$ & 1 (3) \\
Ischemic heart disease & 0 & & & \\
Arrhythmia & & & & 0 \\
\hline
\end{tabular}


pericardial effusion as asymptomatic pericardial effusion. Thus, slight pericardial effusion was considered grade 2 and most grade 2 cases in the present study were a small amount of pericardial effusion. Grade 3 or worse late toxicities of pericardial effusion, ischemic heart disease, and arrhythmia were observed in two (5\%), one (3\%), and four (11\%) patients, respectively. One patient with grade 5 arrhythmia had a history of dilated cardiomyopathy before receiving CRT and was judged medically inoperable because of cardiac dysfunction. Although the causal relationship between arrhythmia and RT was unknown in this case, it was categorized as grade 5 toxicity because we could not rule out a potential relationship. Although the univariate analyses did not show any significant factor to be associated with late cardiac toxicities, grade 3 or worse toxicities tended to be more frequent in patients treated by RT alone or anterior-posterior opposed field (Table 3).

\section{Discussion}

Advances in endoscopic equipment have contributed to the increased detection of early-stage esophageal carcinoma; in addition, the number of patients with superficial esophageal cancer treated by ER has also increased. According to the Registry of Esophageal Carcinomas in Japan, superficial esophageal cancer accounted for 22.7\% of esophageal cancer patients treated in 2001 and 33.4\% in 2011. In the same reports, 11.3 and $17.2 \%$ of patients with esophageal cancer were treated with ER in 2001

Table 3 Late toxicities: cardiac toxicities

\begin{tabular}{|c|c|c|c|c|c|}
\hline \multirow[t]{2}{*}{ Characteristics } & \multirow[t]{2}{*}{$\mathrm{n}$} & \multicolumn{2}{|c|}{$\geq$ Grade 2} & \multicolumn{2}{|c|}{$\geq$ Grade 3} \\
\hline & & $\mathrm{n}(\%)$ & $p$-value & $\mathrm{n}(\%)$ & $p$-value \\
\hline \multicolumn{6}{|l|}{ Age (years) } \\
\hline$\leq 67$ & 19 & $9(47)$ & 1.00 & $4(21)$ & 0.66 \\
\hline$>67$ & 18 & $9(50)$ & & $2(11)$ & \\
\hline \multicolumn{6}{|l|}{ Tumor length $(\mathrm{cm})$} \\
\hline$\leq 3$ & 22 & $9(41)$ & 0.32 & $4(18)$ & 1.00 \\
\hline$>3$ & 15 & $9(60)$ & & $2(13)$ & \\
\hline \multicolumn{6}{|l|}{ Tumor location } \\
\hline $\mathrm{Ce}-U \mathrm{t}$ & 6 & $1(17)$ & 0.18 & $0(0)$ & 0.56 \\
\hline Mt-EGJ & 31 & $17(55)$ & & $6(19)$ & \\
\hline \multicolumn{6}{|l|}{ Treatment } \\
\hline CRT & 24 & $12(50)$ & 1.00 & $2(8)$ & 0.16 \\
\hline RT alone & 13 & $6(46)$ & & $4(30)$ & \\
\hline \multicolumn{6}{|c|}{ History of heart disease } \\
\hline Yes & 9 & $6(67)$ & 0.27 & $2(22)$ & 0.62 \\
\hline No & 28 & $12(43)$ & & $4(14)$ & \\
\hline \multicolumn{6}{|l|}{ Initial field } \\
\hline Anterior-posterior & 20 & $11(55)$ & 0.75 & $5(25)$ & 0.19 \\
\hline Multiple & 17 & $8(47)$ & & $1(6)$ & \\
\hline
\end{tabular}

EGJ Esophagogastric junction and 2011, respectively [1, 17]. Difficulty in the accurate diagnosis of the invasion depth by endoscopic examination and recently expanded indications for ESD, such as tumor of entire circumference or MM invasion, has caused an increase in the number of non-curative resections requiring additional treatment. This study retrospectively analyzed the efficacy and toxicity of salvage RT for superficial esophageal cancer with non-curative ER. The 5-year OS rate was 78\% (95\% CI, 64-91\%), and only one patient died of primary esophageal cancer. Several reports have shown the 5-year OS rate of stage I esophageal cancer patients treated with esophagectomy of approximately $64-78 \%[7,8,18]$. Our results and recent reports of definitive CRT for superficial esophageal cancer were comparable to these results [12-14]. Moreover, RT is less invasive compared to esophagectomy and has obvious advantages for organ preservation. Although previous reports showed RT alone was inferior to CRT in esophageal cancer, we did not observe a significant difference in OS between CRT and RT alone $[12,14,19,20]$. We previously reported the long-term outcome of IBT in combination with EBRT for superficial esophageal cancer [11]. In that report, the most common failure pattern was the primary site, and regional lymph node metastasis tended to occur more frequently in submucosal cases. Resection of the primary tumor by ER may have contributed to local control in the present study. In addition, our results showed good regional control in cases of RT alone. Our cases were clinically judged to be suitable for treatment with ER. Hence, the risk of regional lymph node metastasis might be lower than that of esophageal cancer clinically diagnosed with submucosal invasion with no indications for ER. Although CRT is standard therapy for esophageal cancer, our results suggest that RT alone after non-curative ER might be a worthwhile, less toxic treatment option for patients who are difficult to administer chemotherapy.

The optimal radiation field and efficacy of ENI for esophageal cancer remain controversial. Although a recent meta-analysis did not indicate the effectiveness of ENI, cases of locally advanced esophageal cancer were mainly included [21]. Moreover, the most common failure pattern was local failure in advanced cases [22]. These findings suggest that poor local control may affect the limited contribution of ENI. Furthermore, no multicenter randomized phase III trials have evaluated the effectiveness of ENI for early esophageal cancer. In this study, all patients received ENI and none experienced regional lymph node metastasis, even though they were at risk of subsequent lymph node metastasis. We believe that the use of ENI contributed to this high regional control rate. Early esophageal cancer can achieve high local control rate by CRT compared with advanced cases and higher local control could be expected after ER. 
Thus, the effectiveness of ENI for early esophageal cancer should be investigated focused on this cohort. The concern of RT with ENI is the increased risk of severe cardiopulmonary toxicities. In our study, grade 3 or worth cardiopulmonary toxicities were observed in six patients (16\%), an occurrence rate we considered to be acceptable. However, it is important to reduce the irradiation dose to the heart as much as possible. Although we did not identify any factor associated with late cardiac toxicities, five of them were treated by anteriorposterior field. Recently, the use of multi-portal beams to reduce cardiopulmonary toxicities has become standard in esophageal cancer radiotherapy. Recent advanced techniques such as IMRT or proton therapy have the potential to reduce cardiopulmonary toxicities. Lin et al. reported the efficacy of IMRT for esophageal cancer patients. They observed a significantly higher cumulative incidence of cardiac-related deaths in the 3D-CRT group compared to that in the IMRT group [23]. In addition, they also reported that the use of IMRT may be associated with reduced all-cause, cardiac-related, and othercause mortality in elderly patients with esophageal cancer [24]. Moreover, proton therapy can improve target coverage while reducing the irradiation dose to the surrounding normal tissue compared to photon therapy and proton therapy is expected to achieve high locoregional control and reduce RT-induced toxicity $[25,26]$.

One concern regarding toxicity in this treatment strategy is esophageal stenosis. In our study, although grade 2 esophageal stenosis was observed in seven patients (19\%), they were manageable and severe stenosis was not observed. The reported occurrence rates of esophageal stenosis after ER were $68-94 \%$ for tumor circumferences $\geq 3 / 4$ and were significantly higher in cases with tumor circumference $<3 / 4,[27-29]$. In our study, a tumor circumference $\geq 3 / 4$ was also significantly associated with esophageal stenosis: $\geq 3 / 4$ in six patients and $<$ $3 / 4$ or unknown in one patient $(p<0.001)$. Therefore, the indication for ER should be judged carefully, especially in cases with tumor circumference $\geq 3 / 4$ and high probability for the requirement of additional treatment at clinical diagnosis.

On the basis of the results of the Japan Clinical Oncology Group (JCOG) trial, 60 Gy is considered standard treatment for both locally advanced and early stage esophageal cancer in Japan $[14,30]$. Owing to the lack of the evidence about RT after non-curative ER, we used the same protocol of definitive CRT in the current study. The JCOG 0508 trial is a phase II trial that evaluated the use of the combined ER and CRT for clinical stage I esophageal cancer. In JCOG 0508 trial, patients with clinical stage I submucosal (cSM1-2) esophageal cancer received diagnostic ER and selective CRT based on the histological status. Group A, defined as pathological mucosal invasion with negative resection margin and no LVI, received no additional treatment, while Group B, with pathological SM invasion with negative resection margin or pathological mucosal invasion with LVI, received prophylactic CRT (41.4Gy) and Group C, with pathological SM invasion with positive resection margin, received definitive CRT $(50.4 \mathrm{~Gy})$. The 3-year OS rates were $90.7 \%$ for Group B and $92.6 \%$ in all patients [31]. This result was comparable to that of surgery or CRT for clinical stage I esophageal cancer. Thus, a high dose such as $60 \mathrm{~Gy}$, might not be needed for esophageal cancer after ER.

Metachronous esophageal cancer is a grave issue in patients who have undergone organ preservation treatment for esophageal cancer. The incidence rate of metachronous cancer after ER are 13-14.6\% [32, 33]. In the present study, seven patients (19\%) experienced metachronous cancer and the 5-year incidence rate was 13\%. Five of the seven patients were successfully salvaged by ER. Therefore, the detection of metachronous cancers as superficial lesions by close endoscopic observation is important.

Esophageal cancer patients are at high risk for other malignancies such as head and neck, gastrointestinal, or lung cancers. In our cases, 15 patients (41\%) experienced other malignancy after RT, and the most common cause of death was other malignancies. Early detection of other malignancies is also important after RT since patients with superficial esophageal cancer can expect long-term prognosis.

Our study was limited by its retrospective nature, small number of patients, and variety of RT methods and chemotherapeutic regimens. However, as there are few reports on the long-term results of salvage RT after non-curative ER for superficial esophageal cancer, we think that the results of this study are of great significance. Diagnostic ER and selective CRT based on histological status are likely to become the standard treatment strategy for submucosal esophageal cancer instead of surgery. Our results suggest that RT after ER is a safe and effective treatment while preserving organs and that a longer follow-up is required for the early detection of metachronous esophageal cancer and other malignancies.

\section{Conclusion}

Salvage radiotherapy after non-curative esophageal endoscopic resection is an effective treatment as an organ preservation strategy. Although muscularis mucosae and submucosal cancer have high risks of lymph node metastasis, our results suggest that ENI contributes to reduced regional node metastases. Early detection of metachronous esophageal cancer and other malignancies is important for survivors.

\section{Abbreviations}

CCRT: Concurrent chemoradiotherapy; Cl: Confidence interval;

CRT: Chemoradiotherapy; CT: Computed tomography; CTV: Clinical target 
volume; EBRT: External beam radiotherapy; EGJ: Esophagogastric junction; ENI: Elective nodal irradiation; ER: Endoscopic resection; ESD: Endoscopic submucosal resection; IBT: Intraluminal brachytherapy; IHD: Ischemic heart disease; IMRT: Intensity-modulated radiotherapy; JCOG: Japan Clinical Oncology Group; LN: Lymph nodes; MM: Muscularis mucosae; SM: Submucosal layer; OS: Overall survival; PFS: Progression-free survival

\section{Acknowledgements}

Not applicable.

\section{Authors' contributions}

IN collected clinical data, analyzed it, and drafted the manuscript. YM and YN revised the manuscript. All authors have read and approved the final manuscript.

\section{Funding}

Not applicable.

\section{Availability of data and materials}

Data in the manuscript are available by contacting the corresponding author.

\section{Ethics approval and consent to participate}

This study was approved by the institutional review board of Hiroshima University Hospital.

\section{Consent for publication}

Not applicable.

\section{Competing interests}

The authors declare that they have no competing interests.

\section{Author details}

'Department of Radiation Oncology, Graduate School of Biomedical and Health Sciences, Hiroshima University, 1-2-3 Kasumi, Minami-ku, Hiroshima 734-8551, Japan. ${ }^{2}$ Department of Regeneration and Medicine Medical Center for Translation and Clinical Research, Hiroshima University Hospital, 1-2-3 Kasumi, Minami-ku, Hiroshima 734-8551, Japan. ${ }^{3}$ Department of Gastroenterology and Metabolism, Institute of Biomedical and Health Sciences, Graduate School of Biomedical and Health Sciences, Hiroshima University, 1-2-3 Kasumi, Minami-ku, Hiroshima 734-8551, Japan. ${ }^{4}$ Department of Endoscopy, Hiroshima University Hospital, 1-2-3 Kasumi, Minami-ku, Hiroshima 734-8551, Japan.

Received: 28 September 2019 Accepted: 25 May 2020

\section{Published online: 01 June 2020}

\section{References}

1. Tachimori Y, Ozawa S, Numasaki $\mathrm{H}$, et al. Comprehensive registry of esophageal Cancer in Japan, 2011. Esophagus. 2018;15:127-52.

2. Kodama M, Kakegawa T. Treatment of superficial cancer of the esophagus: a summary of responses to a questionnaire on superficial cancer of the esophagus in Japan. Surgery. 1998;123:432-9.

3. Endo M, Yoshino $K$, Kawano T, Nagai $K$, Inoue $H$. Clinicopathologic analysis of lymph node metastasis in surgically resected superficial cancer of the thoracic esophagus. Dis Esophagus. 2000;13:125-9.

4. Bollschweiler E, Baldus SE, Schröder W, et al. High rate of lymph-node metastasis in submucosal esophageal squamous-cell carcinomas and adenocarcinomas. Endoscopy. 2006;38:149-56.

5. Makuuchi $\mathrm{H}$, Shimada $\mathrm{H}$, Mizutani $\mathrm{K}$, et al. Clinical pathological analysis of surgically resected superficial esophageal carcinoma to determine criteria for deciding on treatment strategy. Diagn Ther Endosc. 1997:3:211-20.

6. Eguchi T, Nakanishi Y, Shimoda T, et al. Histopathological criteria for additional treatment after endoscopic mucosal resection for esophageal cancer: analysis of 464 surgically resected cases. Mod Pathol. 2006:19:475-80.

7. Tachibana M, Yoshimura H, Kinugasa S, et al. Clinicopathological features of superficial squamous cell carcinoma of the esophagus. Am J Surg. 1997;174: 49-53.

8. Igaki $\mathrm{H}$, Kato $\mathrm{H}$, Tachimori $\mathrm{Y}$, et al. Clinicopathologic characteristics and survival of patients with clinical stage I squamous cell carcinoma of the thoracic esophagus treated with three-field lymph node dissection. Eur J Cardiothorac Surg. 2001;20:1089-94.

9. Schweigert M, Dubecz A, Stadlhuber RJ, Muschweck H, Stein HJ. Treatment of intrathoracic esophageal anastomotic leaks by means of endoscopic stent implantation. Interact Cardiovasc Thorac Surg. 2011;12:147-51.

10. Morita M, Nakanoko T, Fujinaka Y, et al. In-hospital mortality after a surgical resection for esophageal cancer: analyses of the associated factors and historical changes. Ann Surg Oncol. 2011;18:1757-65.

11. Murakami Y, Nagata N, Nishibuchi l, et al. Long-term outcomes of intraluminal brachytherapy in combination with external beam radiotherapy for superficial esophageal cancer. Int J Clin Oncol. 2012;17:263-71.

12. Yamada K, Murakami M, Okamoto Y, et al. Treatment results of chemoradiotherapy for clinical stage I (T1NOM0) esophageal carcinoma. Int J Radiat Oncol Biol Phys. 2006 Mar 15;64:1106-11.

13. Murakami Y, Takahashi I, Nishibuchi I, et al. Long-term results of definitive concurrent chemoradiotherapy for patients with esophageal submucosal cancer (T1bNOM0). Int J Clin Oncol. 2015;20:897-904.

14. Kato H, Sato A, Fukuda H, et al. A phase II trial of Chemoradiotherapy for stage I esophageal squamous cell carcinoma: Japan clinical oncology group study (JCOG9708). Jpn J Clin Oncol. 2009;39:638-43.

15. Kam TY, Kountouri M, Roth A, et al. Endoscopic resection with adjuvant chemo-radiotherapy for superficial esophageal squamous cell carcinoma: a critical review. Crit Rev Oncol Hematol. 2018;124:61-5.

16. Mönig S, Chevallay M, Niclauss N, et al. Early esophageal Cancer: the significance of surgery, endoscopy, and Chemoradiation. Ann N Y Acad Sci. 2018:1434:115-23.

17. Ozawa S, Tachimori $Y$, Baba H, et al. Comprehensive registry of esophageal Cancer in Japan, 2001. Esophagus. 2009:6:95-110.

18. Tachibana T, Matono S, Nagano T, et al. Esophagectomy with extended lymphadenectomy for submucosal esophageal cancer: long-term outcomes and prognostic factors. Ann Surg Oncol. 2012;19:750-6.

19. Wong RK, Malthaner RA, Zuraw L, et al. Combined modality radiotherapy and chemotherapy in nonsurgical management of localized carcinoma of the esophagus: a practice guideline. Int J Radiat Oncol Biol Phys. 2003;55:930-42.

20. Wong R, Malthaner R. Combined chemotherapy and radiotherapy (without surgery) compared with radiotherapy alone in localized carcinoma of the esophagus. Cochrane Database Syst Rev. 2006;25:CD002092.

21. Cheng YJ, Jing SW, Zhu LL, et al. Comparison of elective nodal irradiation and involved-field irradiation in esophageal squamous cell carcinoma: a meta-analysis. J Radiat Res. 2018:59:604-15.

22. Minsky BD, Pajak TF, Ginsberg RJ, et al. INT 0123 (radiation therapy oncology group 94-05) phase III trial of combined-modality therapy for esophageal Cancer: high-dose versus standard-dose radiation therapy. J Clin Oncol. 2002;20:1167-74.

23. Lin SH, Wang L, Myles B, et al. Propensity score-based comparison of longterm outcomes with 3-dimensional conformal radiotherapy vs. intensitymodulated radiotherapy for esophageal cancer. Int J Radiat Oncol Biol Phys. 2012;84:1078-85.

24. Lin SH, Zhang N, Godby J, et al. Radiation modality use and cardiopulmonary mortality risk in elderly patients with esophageal Cancer Cancer. 2016:122:917-28.

25. Takada A, Nakamura T, Takayama K, et al. Preliminary treatment results of proton beam therapy with chemoradiotherapy for stage I-III esophageal cancer. Cancer Med. 2016;5:506-15.

26. Xi M, Xu C, Liao Z, et al. Comparative outcomes after definitive Chemoradiotherapy using proton beam therapy versus intensity modulated radiation therapy for esophageal Cancer: a retrospective, single-institutional analysis. Int J Radiat Oncol Biol Phys. 2017;99:667-76.

27. Katada C, Muto M, Manabe T, Boku N, Ohtsu A, Yoshida S. Esophageal stenosis after endoscopic mucosal resection of superficial esophageal lesions. Gastrointest Endosc. 2003;57:165-9.

28. Ono S, Fujishiro $M$, Niimi $K$, et al. Predictors of postoperative stricture after esophageal endoscopic submucosal dissection for superficial squamous cell neoplasms. Endoscopy. 2009:41:661-5.

29. Shi $Q$, Ju H, Yao LQ, et al. Risk factors for postoperative stricture after endoscopic submucosal dissection for superficial esophageal carcinoma. Endoscopy. 2014;46:640-4

30. Kato K, Muro K, Minashi K, et al. Phase II study of Chemoradiotherapy with 5-fluorouracil and Cisplatin for stage II-III esophageal squamous cell carcinoma: JCOG trial (JCOG 9906). Int J Radiat Oncol Biol Phys. 2011:81:684-90. 
31. Minashi K, Nihei K, Mizusawa J, et al. Efficacy of Endoscopic Resection and Selective Chemoradiotherapy for Stage I Esophageal Squamous Cell Carcinoma. Gastroenterology. 2019;157:382-90 e3.

32. Shimizu Y, Tukagoshi H, Fujita M, Hosokawa M, Kato M, Asaka M. Metachronous squamous cell carcinoma of the esophagus arising after endoscopic mucosal resection. Gastrointest Endosc. 2001;54:190-4.

33. Urabe Y, Hiyama T, Tanaka S, et al. Metachronous multiple esophageal squamous cell carcinomas and Lugol-voiding lesions afterendoscopic mucosal resection. Endoscopy. 2009;41:304-9.

\section{Publisher's Note}

Springer Nature remains neutral with regard to jurisdictional claims in published maps and institutional affiliations.

Ready to submit your research? Choose BMC and benefit from:

- fast, convenient online submission

- thorough peer review by experienced researchers in your field

- rapid publication on acceptance

- support for research data, including large and complex data types

- gold Open Access which fosters wider collaboration and increased citations

- maximum visibility for your research: over $100 \mathrm{M}$ website views per year

At $B M C$, research is always in progress.

Learn more biomedcentral.com/submissions 